\title{
OS ESPAÇOS PSIQUIÁTRICOS
}

Letícia Gargantini Miranda', Maria Alessandra Bacaro Boscoli²

${ }^{1}$ Discente do curso de Arquitetura e Urbanismo da Universidade do Oeste Paulista (UNOESTE). ${ }^{2}$ Docente do curso de Arquitetura e Urbanismo da Universidade do Oeste Paulista (UNOESTE).

\section{RESUMO}

Ao longo da história, houve muitas modificações no tratamento do portador de sofrimento psíquico. Porém, até hoje não há um tratamento eficaz para esses doentes. As últimas modificações ocorridas no Brasil, em relação à tentativa de melhorar esta situação, trazidas pela Reforma Psiquiátrica, trouxeram poucos avanços em meio há muitos problemas. O que falta é inserir medidas humanizadas no tratamento do portador de sofrimento psíquico e aumentar sua integração com a própria família e a sociedade. A arquitetura vem se mostrando uma eficaz ferramenta para trazer humanização aos espaços psiquiátricos e sua integração com a sociedade. Foi pensando nesses benefícios que este trabalho foi desenvolvido, com objetivo de discutir sobre a necessidade de existir espaços psiquiátricos adequados. Este trabalho começou com pesquisas sobre a história da psiquiatria e com a busca pelos espaços psiquiátricos que existem atualmente, para perceber o que há de eficaz e o que precisa ser modificado.

Palavras-chave: portador de sofrimento psíquico, reforma psiquiátrica, arquitetura, humanização, espaços psiquiátricos.

\section{INTRODUÇÃO E OBJETIVO}

Desde os primórdios da psiquiatria ocorreram grandes avanços no modelo assistencial, na humanização do atendimento e no tratamento do doente mental, porém continuamos a olhar as instituições de saúde mental e seus pacientes com estranheza. A doença mental, até hoje, é considerada um assunto evitado. A velha idéia de que os "loucos" precisam ficar em ambientes fechados e isolados do resto da população ainda está muito intrínseca em nosso meio, como método de controle dos doentes e de proteção da sociedade. Por isso ainda há muito que se fazer para que esta idéia se modifique e os doentes garantam seus direitos.

Para tentar mudar esta visão, o Ministério da Saúde criou a reforma psiquiátrica, que visa a desospitalização, ressocialização dos pacientes e da humanização dos tratamentos, através da adoção de modelos que acabem os hospitais psiquiátricos e suas técnicas de alienação e exclusão social.

Porém o Ministério da Saúde aprovou a reforma psiquiátrica sem antes criar novos meios eficazes para tratar os doentes. Preocupam-se em fechar hospitais psiquiátricos e reduzir leitos sem se importar realmente com o portador de sofrimento psíquico. 
Incorporar medidas humanizadas, aumentar a integração do doente internado com a família e com a sociedade é uma forma de resolver todas as necessidades do doente. Uma medida eficaz é aliar a arquitetura e saúde para contribuir com a modernização dos hospitais psiquiátricos, ajudando-os a subtrair as características manicomiais, tornando esses lugares mais humanizados de modo a colaborar no processo de interação e reinserção destes indivíduos na sociedade.

Foi pensando neste problema que a saúde mental está passando, no descaso e na falta de tratamento que o doente vem sofrendo, que este trabalho foi desenvolvido. O objetivo é discutir sobre a falta de espaços para tratar o portador de sofrimento psíquico e mostrar a necessidade de existir lugares humanizados e especializados para o tratamento desses doentes.

\section{METODOLOGIA}

O desenvolvimento deste trabalho começou com pesquisas sobre a história da psiquiatria, seus avanços relacionados ao tratamento do portador de sofrimento psíquico e a busca de métodos eficazes para a criação de um espaço psiquiátrico humanizado. Outra medida tomada foi à busca pelos espaços psiquiátricos que existem atualmente, para perceber o que há de eficaz e o que precisa ser modificado.

\section{DISCUSSÃO}

O espaço destinado à assistência aos enfermos, necessitados e portadores de distúrbios mentais tem sofrido inúmeras modificações ao longo de sua história, refletindo as próprias transformações sofridas pela civilização. (ALEXANDER e SELESNICK, 1980)

De acordo com Alexander e Selesnick (1980, p.23) desde as primeiras civilizações há um modo de se relacionar com o doente mental e sua doença:

Sempre ouve entre nós doentes mentais - que eram temidos, admirados, ridicularizados, lamentados ou torturados, mas muito raramente curados. Sua existência abala-nos até o fundo do nosso ser, pois nos torna dolorosamente conscientes de que a sanidade mental é uma coisa frágil.

Até o século XVIII o espaço destinado aos doentes estava vinculado as práticas religiosas, depois disso, passou a ser mais racional e científico. O hospital deixou de ser o lugar onde se aguardava a morte e passou a representar um espaço de busca da cura, sob a coordenação do médico. (ALEXANDER e SELESNICK, 1980)

Não é a toa que a primeira especialidade da medicina (séc XVIII) foi a psiquiatria, pois a doença mental está ligada a essência da natureza do homem, portanto desde os tempos 
primitivos tentamos compreende-la e tratá-la. Na pré-história estava a cargo dos médicos feiticeiros, com o passar do tempo chegou a vez dos religiosos, filósofos, depois dos médicos, artistas, cientistas, até chegar ao médicos especializados: os psiquiatras. (ALEXANDER e SELESNICK, 1980)

No Brasil, só depois da chegada da família real, em 1808, que o louco começou a ser notado pelo Estado. (AMARANTE, 1998)

Com o crescimento econômico e mudanças na sociedade, os loucos não mais poderiam perambular pelas ruas. Desta forma, a medicina é chamada para fazer o controle social e dar um destino para eles. Os loucos começaram a fazer parte das casas de correção, prisões, asilos de mendigos ou dos porões das Santas Casas de Misericória. Raramente eram encontrados sendo tratados em hospitais. (AMARANTE, 1998)

Esta situação, em 1830 se modificou um pouco. Pela iniciativa da Comissão da Sociedade de Medicina do Rio de Janeiro, os loucos começam a ser vistos de outra forma, vistos como doentes mentais, que merece um espaço próprio e tratamento. (AMARANTE, 1998)

Para dar assistência aos doentes mentais foram criadas as colônias de alienados, que tinham o intuito de integrar o louco e a sociedade, tanto em casa como no trabalho. Com a implantação dessas novas medidas representaram a primeira reforma psiquiátrica no Brasil. (AMARANTE, 1998)

Nos anos 30, descobriram métodos como os choques insulínico e cardiazólico, a eletroconvulsoterapia e a lobotomia. Com isso, acreditavam ter obtido a cura para as doenças mentais. A psiquiatria se torna mais poderosa e os asilamentos mais freqüentes, aumentam as vagas nos asilos e são criados centros cirúrgicos para as lobotomias. (AMARANTE, 1998)

$\mathrm{Na}$ década de 50 surgiram os primeiros neurolépticos. Mesmo com o crescimento dos pacientes, a assistência psiquiátrica era realizada apenas dentro dos hospitais psiquiátricos. Não ocorria nenhum tipo de avanço na desintitucionalização e na desospitalização. (AMARANTE, 1998)

Em 60, a doença mental se torna um objeto de lucro. É criado o Instituto Nacional de Previdência (INPS) e o Estado começa a comprar serviços privados. Com isso, aumenta o numero de vagas em hospitais psiquiátricos particulares. São criadas novas propostas não manicomiais, planos de psiquiatria preventiva, comunidades terapêuticas como o Plano Integrado de Saúde Mental (PISAM), e outras propostas de atenção primária, que não são bem aceitas pela falta de aprovação das medidas de superação asilar. (AMARANTE, 1998) 
No final dos anos 70, após o movimento sanitário e enquanto o modelo hospitalocêntrico decaía e cresciam os movimentos pelos direitos dos doentes psiquiátricos, nasceu um novo processo de Reforma Psiquiátrica no Brasil com o intuito de desenvolver mudanças na saúde mental e de vencer a violência asilar. (BRASIL. Ministério da Saúde, 2005)

O Movimento dos Trabalhadores em Saúde Mental (MTSM) foi o protagonista da Reforma Psiquiátrica, criado em 1978 e formado por integrantes do movimento sanitário, pacientes psiquiátricos e familiares, sindicalistas e profissionais da saúde. O MTSM denuncia a violência manicomial, o saber psiquiátrico e o modelo hospitalocêntrico. Uma das inspirações para a reforma vem da experiência italiana de desinstitucionalização psiquiátrica e a crítica ao manicômio. (BRASIL. Ministério da Saúde, 2005)

No ano de 1989, o deputado Paulo Delgado cria um projeto de lei para revisar os direitos dos doentes mentais e findar gradualmente os hospitais psiquiátricos do país, substituindo-os por uma rede de atenção à saúde mental, que são os serviços de atenção diária, CAPS, NAPS e os Hospitais-Dia, conferindo a eles o valor estratégico para a mudança do modelo hospitalocêntrico. Na década de 90 entram em vigor as normas federais para a introdução do modelo de atenção comunitário. (BRASIL. Ministério da Saúde, 2005)

Esta rede é composta por Centros de Atenção Psicossocial (CAPS), Serviços Residenciais Terapêuticos (SRT), Centros de Convivência, Ambulatórios de Saúde Mental e Hospitais Gerais. (BRASIL. Ministério da Saúde, 2005)

Esta luta antimanicomial, que surgiu com o Movimento dos Trabalhadores em Saúde Mental, em 1978, tinha verdadeiramente o intuito de lutar por melhores condições de trabalho, melhores remunerações. Percebe-se, então, que esse não foi um movimento de pacientes e de seus familiares para acabarem com os manicômios, foi apenas um desejo dos enfermeiros, psicólogos, jovens psiquiatras, assistentes sociais e médicos, em melhorar suas condições trabalhistas. (FILHO, 2003)

O movimento dos trabalhadores, até hoje, visa condições mais agradáveis de trabalho, dessa forma os casos mais graves foram deixados de lado e o mais adequados para o modelo criado, a rede de atenção à saúde mental, estão sendo atendidos. (FILHO, 2003)

Por isso Brasil vem enfrentando, na rede pública de saúde, uma grande crise: a desassistência de pacientes mentais. Entre 2001 e 2006, o número de morte de doentes mentais cresceu 41\%. Passou de 6.655 para 9.398. Isso é resultado do fechamento de um quarto dos leitos psiquiátricos do país, sem criar serviços substitutos suficientes e capacitados. (O GLOBO, 2007) 
Outro problema da reforma é que, quando os hospitais são fechados, os doentes ficam sem destino. Valentim Gentil Filho (2003, p. 20) questiona esse ponto:

Onde foram parar as pessoas "desinternadas", os novos doentes graves e o dinheiro? Tenho sérias críticas a essa política irresponsável. Houve imprevidência e tentou-se resolver "revolucionariamente" uma questão muito complexa, que não é a única do Brasil.

Com a diminuição de leitos nos hospitais psiquiátricos e a falta de local para abrigar os doentes mentais, eles estão indo parar nas ruas ou em cadeias. O presidente da Associação Brasileira de Psiquiatria (ABP), Antônio Geraldo da Silva (apud CHAVES, 2012), confirma esta questão:

"O que foi proposto no Brasil resultou em moradores de rua doentes mentais e doentes na cadeia, transformando os presídios em manicômios, mostrando que o modelo é tão falido quanto o hospitalocêntrico."

O governo se comprometeu a criar leitos em hospitais gerais além da rede de atendimento comunitário. Mas, até 2007, apenas 2.400 leitos tinham sido criados em hospitais gerais, em contrapartida, 12.551 leitos foram fechados nos hospitais psiquiátricos. Os CAPS, criados para substituir os hospitais psiquiátricos, não possuem capacidade de cuidar dos casos mentais mais graves, eles não são unidades de cuidados intensivos em psiquiatria. Pois nem os CAPS 24 horas são capazes de acompanhar os doentes agudos. Desta forma, esses doentes estão em algum manicômio ainda existente, em pronto-socorros, com as famílias ou presos em cadeias, sendo que nenhum destes meios possui capacitação de cuidar do doente, pois os agudos precisam de um centro de cuidados intensivos, onde passem por exames e comecem a ser acompanhados por profissionais. (FILHO, 2003)

Entre as principais recomendações da Reforma Psiquiátrica estão a prática da desospitalização e ressocialização dos pacientes e da humanização dos tratamentos, através da adoção de modelos que substituam os antigos manicômios e suas técnicas de alienação exclusão social. (BRASIL. Ministério da Saúde, 2005)

Incluir o doente na sociedade é uma questão que esta sendo usada amplamente, porém, em muitos casos, a palavra inclusão não possui um significado social. A inclusão é muito discutida, mas poucas medidas são tomadas para realmente inserir o doente na sociedade. (ARANHA, S.D.)

A exclusão é uma questão presente desde o início da história da doença mental, e continua até hoje muito intrínseca em nosso meio. Retirar o doente mental da família, do 
mercado de trabalho, dos vínculos sociais sempre foi, e continua sendo o meio mais eficaz para o doente, e principalmente para a sociedade. (MACIEL, 2008)

O que justifica esta idéia é que a exclusão veio para proteger a sociedade dos atos que os doentes possam cometer e para poder ensiná-los as regras para viver dentro dos padrões vigentes. (RODRIGUES, 2007)

O governo e seus profissionais estão mais interessados com a relação que o doente mental terá com a sociedade, do que com o real estado, direito e necessidade do doente. (RODRIGUES, 2007)

Rodrigues (2007) questiona esta estranha relação entre a sociedade e doente mental:

A sociedade adoece as pessoas e, em a doença se manifestando publicamente, as exclui, punindo-as por terem deixado de se "enquadrar" nas exigências, necessidades e nos modelos coletivos. Em seguida, tenta recuperá-las recorrendo aos mesmos instrumentos ou mecanismos de controle que as adoeceram. Tão paradoxal quanto o afastamento do doente mental do convívio social para adequá-lo ao espaço social do qual fazem parte é a utilização de técnicas igualmente opressoras e semelhantes às causas do distúrbio.

É possível verificar iniciativas de remodelar a arquitetura das instituições psiquiátricas, trazendo humanização às estruturas manicomiais, diminuindo o isolamento e a exclusão dos pacientes. O conceito de humanização está sendo aplicado em muitos projetos de arquitetura saúde e tem como característica focar no usuário, para propiciar seu bem-estar físico e emocional. (LUIZ, S.D.)

Fontes (2004, p. 59), fala sobre o enfoque que a saúde vem dando a um atendimento humanizado:

A abordagem do espaço arquitetônico como principiador do bem-estar físico e emocional de seus usuários tem merecido crescente valorização nos processos de planejamento em saúde pública. O conceito de humanização do atendimento tem sido largamente aplicado nos mais recentes projetos de arquitetura da saúde, representando o desdobramento de um novo enfoque, centrado no usuário, que passa a ser entendido de forma holística, como parte de um contexto, e não mais como um conjunto de sintomas e patologias a serem estudadas pelas especialidades médicas [...] $\mathrm{Na}$ arquitetura, verificam-se iniciativas de adequação das antigas estruturas asilares ao conceito de humanização e aos modelos preconizados pela reforma, em detrimento dos antigos conceitos de isolamento e exclusão. Essas iniciativas acontecem de maneira diferenciada em cada instituição, segundo suas especificidades de demandas, estrutura física e diretrizes administrativas. 
Contribuir para a anulação da imagem negativa proporcionada pelo manicômio é um desafio a ser assumido pela arquitetura, pois para desenvolver um projeto arquitetônico hospitalar humanizado é importante integrar profissionais de arquitetura, saúde coletiva e psicologia social. (FONTES, 2004)

\section{RESULTADOS}

Em 2007, o Brasil tinha 16,5 milhões de portadores de sofrimento psíquico que necessitava de internações e mais de 20 milhões possuíam doenças mentais mais leves. Com o passar dos anos, a população brasileira e a doença mental só vem aumentando e os meios para trata la, esta há cada dia mais precário. (O GLOBO, 2007)

Com isso vemos a necessidade de criar novos espaços psiquiátricos, que tratem o portador de sofrimento psíquico de forma adequada e segura, que realize um tratamento eficaz, coloque a humanização como um dos principais pontos e que não exclua o doente do resto da sociedade.

\section{CONCLUSÃO}

Até hoje a saúde mental está evoluindo e procurando uma melhor maneira de tratar seus doentes de uma forma eficiente e humanizada. Porém ainda há muito que se fazer para chegar a um método eficaz.

Uma ferramenta útil para esse processo é aliar arquitetura e saúde, isso contribui com a modernização dos hospitais psiquiátricos, colabora com a interação e reinserção dos doentes na sociedade, construindo um espaço humanizado e eficiente para o tratamento dos portadores de sofrimento psíquico.

\section{REFERENCIAS}

ALEXANDER, F.; SELESNICK S. A história da psiquiatria: uma avaliação do pensamento e da prática desde os tempos primitivos até o presente. 2 ed. São Paulo: Instituição Brasileira de Difusão Cultural S. A., 1980

AMARANTE, P. Psiquiatria social e reforma psiquiátrica. 2 ed. Rio de Janeiro: Fiocruz, 1998.

ARANHA, M. Paradigmas da relação da sociedade com as pessoas com deficiência. S.D. $24 f$. Universidade Estadual de São Paulo - UNESP, Marília

Sem hospícios, morrem mais doentes mentais. 0 globo, São Paulo, 9 dez. 2007. 0 país, p. 14

FILHO, V. Políticas de saúde mental. São Paulo, 2003 
FONTES, M. Saúde e arquitetura: caminhos para humanização dos ambientes hospitalares. 1 ed. Rio de Janeiro: Senac, 2004.

Maciel S. C. et. al. Exclusão social do doente mental: discursos e representações no contexto da reforma psiquiátrica. 2008. 10f. (Psicologia) - Universidade Federal da Paraíba - UFP, Paraíba.

BRASIL. Ministério da Saúde, 2005.

CARMELITA RODRIGUES. Loucura e exclusão social. Brasília. 8 agos. 2007. Disponível em < www.psicopauta.wordpress.com >. Acesso 15 maio 2013.

GLAUCIA CHAVES. Decisão do Brasil de mudar tratamento de pacientes mentais provoca polêmica. Brasília. 8 jan. 2012. Disponível em < www.correiobraziliense.com.br>. Acesso em 9 maio 2013 